\title{
Nonprobative photographs (or words) inflate truthiness
}

\author{
Eryn J. Newman • Maryanne Garry • \\ Daniel M. Bernstein • Justin Kantner • \\ D. Stephen Lindsay \\ Published online: 7 August 2012 \\ (C) Psychonomic Society, Inc. 2012
}

\begin{abstract}
When people evaluate claims, they often rely on what comedian Stephen Colbert calls "truthiness," or subjective feelings of truth. In four experiments, we examined the impact of nonprobative information on truthiness. In Experiments $1 \mathrm{~A}$ and $1 \mathrm{~B}$, people saw familiar and unfamiliar celebrity names and, for each, quickly responded "true" or "false" to the (betweensubjects) claim "This famous person is alive" or "This famous person is dead." Within subjects, some of the names appeared with a photo of the celebrity engaged in his or her profession, whereas other names appeared alone. For unfamiliar celebrity names, photos increased the likelihood that the subjects would judge the claim to be true. Moreover, the same photos inflated the subjective truth of both the "alive" and "dead" claims, suggesting that photos did not produce an "alive bias" but rather a "truth bias." Experiment 2 showed that photos and verbal information similarly inflated truthiness, suggesting that the effect is not peculiar to photographs per se. Experiment 3 demonstrated that nonprobative photos can also enhance the truthiness of general knowledge claims (e.g., Giraffes are the only mammals that cannot jump). These effects add to a growing literature on how nonprobative information can inflate subjective feelings of truth.
\end{abstract}

Electronic supplementary material The online version of this article (doi:10.3758/s13423-012-0292-0) contains supplementary material, which is available to authorized users.

E. J. Newman $\cdot$ M. Garry $(\bowtie)$

School of Psychology, Victoria University of Wellington,

P.O. Box 600 Wellington, New Zealand 6140

e-mail: Maryanne.Garry@vuw.ac.nz

D. M. Bernstein

Kwantlen Polytechnic University,

British Columbia, Canada

J. Kantner · D. S. Lindsay

University of Victoria,

British Columbia, Canada
Keywords Memory $\cdot$ Relative judgment $\cdot$ Cognitive fluency

"I am no fan of dictionaries or reference books," says comedian Stephen Colbert, "constantly telling us what is or isn't true." Instead of looking up claims in a book, Colbert urges viewers to "try looking it up in your gut." This is truthiness: "truth that comes from the gut, not books." Of course, when people evaluate claims, they use both rational thinking and intuitive hunches - often doing so, as Colbert implied, without having access to the facts. A century of research has shown that these intuitive judgments are susceptible to influence from general beliefs, prejudices, and expectations; from features of the current context, such as demand characteristics; and from aspects of past experience that interact with the present to privilege the accessibility of some memories over others (Bransford \& Johnson, 1972; Henkel \& Mather, 2007; Kunst-Wilson \& Zajonc, 1980; Lindsay, 2008). In this article, we will use the term "truthiness effect" to refer to a category of phenomena in which - when making rapid judgments about the truth of a claim - nonprobative information about a stimulus or situation causes people to shift toward believing that claim.

Suppose, for instance, that you evaluate the claim "Stephen King is alive." You are probably familiar with Stephen King. The cognitive literature suggests that you will try to retrieve information from memory - related knowledge, thoughts, and images - to help you decide whether or not he is alive (Graesser \& Hemphill, 1991). We know from research on confirmation bias that people search for information that supports their hypotheses, perhaps because (as per Spinoza's notion) comprehending a claim entails representing it as true, whereas falsifying it requires a secondary, more effortful step (Gilbert, Tafarodi, \& Malone, 1993; Nickerson, 1998). So, given the claim "Stephen King is alive," you might mentally test the hypothesis that he is indeed alive: You "see" recent images of him, "hear" him on NPR, or "remember" seeing advertisements for his latest book. The fluency with which you generate these alive-consistent thoughts and images may 
bolster their perceived currency. And so you conclude that the claim is true.

But now suppose that you evaluate the claim "John Key is alive." We suspect that most readers know little to nothing about John Key. You might think "John Key? Not sure if I've heard of him. I have no idea whether he's alive." You might be unable to conjure thoughts and images to help you evaluate whether the claim is true, and your only recourse would be to guess. But nonprobative information can affect people's guesses in the moment. Indeed, several lines of research lead us to speculate that when a claim appears with a photograph, such as the one of John Key in Fig. 1 below, the photo might bias people to guess that the claim is true.

We know from studies of cognitive fluency that presenting information in a semantically rich context can facilitate conceptual processing and lead to illusions of familiarity in the moment. For example, people more often claim that they have studied a target word (e.g., "boat") earlier when the test word appears in a semantically predictive sentence ("The stormy seas tossed the boat") rather than in a neutral sentence ("He saved up his money and bought a boat"; Whittlesea, 1993). The semantically predictive context is thought to help people anticipate the final word, producing unexpectedly fluent conceptual processing, which they take as evidence of familiarity-leading them to say that they have recently seen the word. This finding also fits with the literature on cognitive availability: Repeated or semantically primed information is easily retrieved from memory, and people often conclude-sometimes falsely-that easy retrieval signals frequency, familiarity, and truth (Begg, Anas, \& Farinacci, 1992; Kelley \& Lindsay, 1993; Tversky \& Kahneman, 1973; Whittlesea, 2011).

This literature suggests that in a single presentation, photos might provide a semantically rich context, making details about an otherwise unfamiliar name more available. Thus, photos should bootstrap the generation of thoughts and images that subjects may then be biased to construe as evidence that the claim in question is true. To understand our thinking, reconsider the claim about John Key, but this time look at the photo in Fig. 1. Suddenly you know a little more about him. You might think "He's probably some kind of political figure - I see a flag, and microphones with media logos. The flag has part of the Union Jack-looks like it's from Australia or maybe New Zealand. . .." The photo is related to the claim and is nonprobative-it does not tell you whether John Key is alive-but the information you glean from that photo might nonetheless enable you to do a better job of imagining that the claim is true.

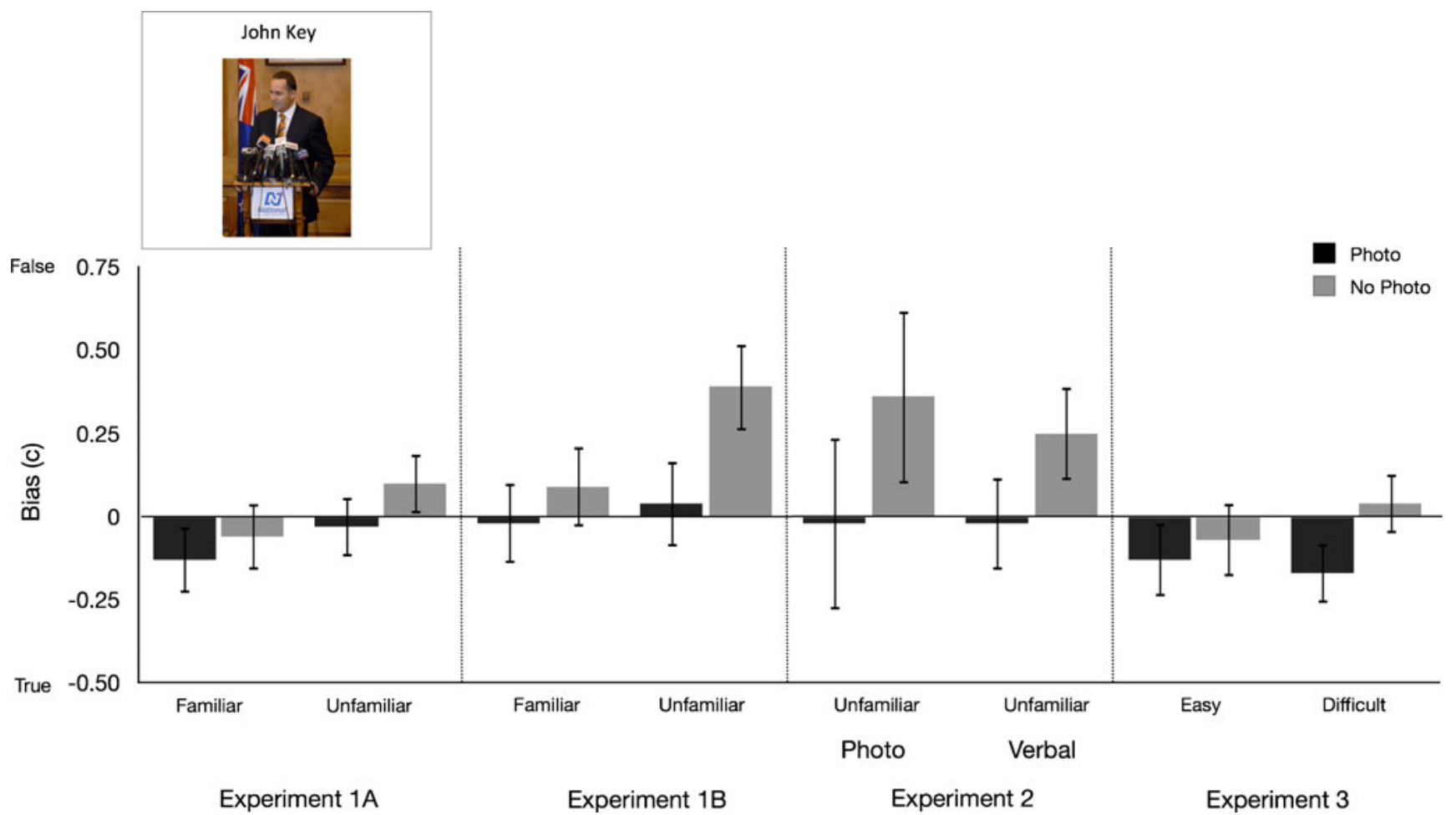

Fig. 1 Bias for claims about familiar and unfamiliar names (in Exps. 1A, $1 \mathrm{~B}$, and 2) or for easy and difficult trivia statements (in Exp. 3), presented with or without a photograph and collapsed across the Dead/Alive factor (in Exps. 1A, 1B, and 2). Negative values of $c$ indicate a bias to respond "true." In Experiments 1 and 2, photos (or words) affected bias for unfamiliar names; in Experiment 3, photos affected bias for difficult trivia statements. The error bars show $95 \%$ within-subjects confidence intervals for the photo/no-photo effect at each level of familiarity or difficulty (see Masson \& Loftus, 2003). The photo is presented courtesy of the New Zealand National Party, under a Creative Commons license 
Related lines of research have shown that when people can easily imagine a target, they often conclude-only moments later-that a claim about it is more likely to occur (Sherman, Cialdini, Schwartzman, \& Reynolds, 1985; see Alter \& Oppenheimer, 2009, for a review). Photos should provide the raw materials for imagery, thereby facilitating generation of the rich perceptual and conceptual details that people typically interpret as cues to reality (e.g., Johnson, 2006). Moreover, people are inclined to trust photos, which are often the best evidence that something actually occurred (Kelly \& Nace, 1994). So, even if photos do not provide probative evidence for a target claim (like the photo in Fig. 1), they might nonetheless boost belief in the claim, because photos are inherently credible in themselves. In a particularly worrisome example of this sort of bias, students rated the scientific reasoning of a neuroscience article more favorably if the article included an image of the brain (McCabe \& Castel, 2008).

This body of research suggests that photos might boost the truthiness of claims by bootstrapping the generation of related ideas and images, or by creating an aura of plausibility simply because people find photos to be credible. Many studies have demonstrated that imagination or repeated exposure to claims can - over time - produce illusions of truth, belief, and memory (Bernstein, 2005; Brown \& Marsh, 2008; Garry, Manning, Loftus, \& Sherman, 1996; Lindsay, Hagen, Read, Wade, \& Garry, 2004). Here we propose that a claim coupled with a related but nonprobative photo might, in the moment, combine with confirmation bias to produce immediate truthiness (cf. Hansen \& Wänke, 2010).

In our first two experiments, we showed people familiar and unfamiliar celebrity names; half of the celebrities were alive. The celebrity names appeared either with or without a photo. For each name, we asked some subjects to judge the truth of the claim "This famous person is alive." The photos depicted celebrities alive, which might be taken as evidence of celebrities being alive. Therefore, we asked another group of subjects to respond to the claim "This famous person is dead." If photos help people generate hypothesis-consistent thoughts and images about unfamiliar celebrities, then photos should increase the truthiness of claims about those celebrities, regardless of whether the claim is that the celebrity is alive or dead (cf. Unkelbach, 2007).

\section{Experiments 1A and 1B}

Method

Subjects In Experiment 1A, 92 undergraduate psychology students from Victoria University of Wellington, New
Zealand, participated for course credit. In Experiment 1B, 48 undergraduate psychology students from the University of Victoria, Canada, participated for optional bonus points.

Design We used a 2 (photograph: yes, no) $\times 2$ (familiarity: familiar, unfamiliar) $\times 2$ (claim: alive, dead) mixed design, manipulating photograph and familiarity within subjects and claim between subjects.

Procedure On the basis of data from preliminary norming, we assembled sets of low- and moderate-familiarity celebrity names; for brevity, we refer to these as "unfamiliar" and "familiar" celebrities. Half of these celebrities were alive, and the names of the dead and alive celebrities were equated on familiarity (on a 5-point scale, $M_{\text {Alive }}=2.89, S D_{\text {Alive }}=$ $\left.0.62 ; M_{\text {Dead }}=2.87, S D_{\text {Dead }}=0.58\right)$ and represented a similar range of eras and professions.

We used Macintosh iBook G4 computers and PsyScope software to present 80 celebrity names- 40 familiar and 40 unfamiliar - to subjects. The names appeared, individually, in large black font against a white background. On half of the trials, subjects saw a photo of the celebrity engaged in his or her profession - for example, John Key, the current New Zealand prime minister, standing at a podium with microphones and a New Zealand flag (see Fig. 1).

The order of the names was randomized for each subject and we counterbalanced so that names appeared equally often with or without a photo, which was orthogonal to the alive/dead and low/high familiarity variables. Subjects learned that sometimes they would see a photo and sometimes they would not. We did not provide any further instructions about how they should use the photo. As each name or name-photo pair appeared, we asked half of our subjects to decide the truth of the claim "This famous person is alive" and the other half to decide the truth of the claim "This famous person is dead." We asked the subjects to respond "as quickly as possible, but not so quickly that you start making errors," and asked them to respond within $3 \mathrm{s.}^{1}$

Experiment 1B, a replication, followed the same procedure, but with new sets of "unfamiliar" and "familiar" celebrities assembled after new norming with Canadian students. The subjects saw 84 celebrity names, presented using E-Prime software (Psychology Software Tools Inc., Sharpsburg, PA) on PCs.

\footnotetext{
${ }^{1}$ In Experiment 1A, we did not record data for trials in which the responses exceeded $3 \mathrm{~s}$, which happened on $9.62 \%$ of trials, but in Experiment 1B, we recorded and analyzed all response times. Also, because of a programming error, two celebrity names appeared in the incorrect counterbalance; we excluded those names from the analyses, but we found the same (significant) pattern of results when we did include them.
} 


\section{Results}

We calculated people's bias (c) to say that a claim was true (Stanislaw \& Todorov, 1999). ${ }^{2}$ Figure 1 shows that across Experiments $1 \mathrm{~A}$ and $1 \mathrm{~B}$, the black bars are relatively more negative than the gray bars, indicating that pairing a claim with a photo led people to be more inclined to say that the claim was true. Relative to the no-photo control, people were more biased to respond "true" (i.e., lower values of $c$ ) when photos accompanied the names [Exp. $1 \mathrm{~A}, F(1,90)=$ $4.87 \eta_{\mathrm{p}}{ }^{2}=.05$; Exp. 1B, $\left.F(1,46)=10.53, \eta_{\mathrm{p}}{ }^{2}=.19\right]$. In both experiments, the effect of photos tended to be larger for unfamiliar names [Exp. 1A, $t_{\text {unfam }}(91)=2.21$; Exp. 1B, $\left.t_{\text {unfam }}(47)=3.74\right]$ than for familiar names [Exp. 1A, $t_{\text {fam }}(91)=$ 1.02, n.s.; Experiment $\left.1 \mathrm{~B}, t_{\text {fam }}(47)=1.25, p=.22\right]$, although the Photo $\times$ Familiarity interaction was significant only in Experiment $1 \mathrm{~B}, F(1,46)=5.40, \eta_{\mathrm{p}}{ }^{2}=.11$, not in Experiment $1 \mathrm{~A}, F(1,90)<1$.

Truthiness or aliveness? Consistent with our hypothesis that photos promoted truthiness, not aliveness, claim (dead or alive) did not interact with photos $(F<2)$. There was a nonsignificant Photo $\times$ Familiarity $\times$ Claim interaction in Experiment $1 \mathrm{~B}, F(1,46)=2.62, p=.11$; this interaction was also nonsignificant in Experiment $1 \mathrm{~A}, F<1$.

Interestingly, people tended to find "alive" claims to be true more often than "dead" claims. In Experiment 1A, this pattern was most pronounced for familiar names [Familiarity $\times$ Claim interaction, $F(1,90)=13.05, \eta_{\mathrm{p}}{ }^{2}=.13 ; t_{\text {fam }}(91)=4.63$, $\left.t_{\text {unfam }}(91)<1\right]$. In Experiment $1 \mathrm{~B}$, a similar tendency occurred for all names, $F(1,46)=3.94, p=.05, \eta_{\mathrm{p}}{ }^{2}=.08$.

\section{Discussion}

As predicted, photos led to a truth bias for unfamiliar celebrity names. These results fit with a mechanism relating to cognitive availability: Photos might promote truthiness because they provide a rich semantic context that facilitates the generation of thoughts and images relating to the claim. But these results also fit with the idea that feelings of truthiness arose because photos are inherently credible; people often regard photos as evidence of reality. Indeed, Kelly and Nace (1994) showed that people trust photos even when they distrust the source in which they appear (e.g., the National Enquirer). In a result perhaps related to this finding, McCabe and Castel (2008) found that in contrast to photorealistic images of the brain, bar graphs did not enhance ratings of the scientific reasoning in an article (see also Keehner, Mayberry, \& Fischer, 2011). In

\footnotetext{
$\overline{2}$ Table 1 in the Supplemental Materials provides a brief summary of the results of parallel $d^{\prime}$ analyses.
}

Experiment 2, we examined whether the unique characteristics of photos are essential ingredients in producing truthiness. To address this question, we compared the effect of photos to the effect of verbal descriptions of those photos. If these verbal descriptions also produce truthiness, it would suggest that when people lack knowledge, anything that makes it easier for people to generate thoughts and images related to a claim should bias them toward believing that claim.

\section{Experiment 2}

Method

Subjects A group of 54 undergraduate students from the University of Victoria, Canada, participated for optional bonus points.

Design We used a 2 (nonprobative information: yes, no) $\times 2$ (format of nonprobative information: photo, verbal) $\times 2$ (claim: alive, dead) mixed design. We manipulated the format (photo vs. verbal) and claim (dead vs. alive) between subjects, and also reduced the design by including only the condition that produces truthiness: unfamiliar names.

Materials and procedure The subjects saw 52 names, which comprised 40 of the critical unfamiliar names from Experiment $1 \mathrm{~B}$ and 12 moderate-familiarity celebrity names. We included a few moderate-familiarity names as fillers in order to make the task easier and more engaging for the subjects.

Half of the subjects saw a photograph of the celebrity paired with half of the names, and the other half saw a verbal description of the celebrity instead of a photo. We created verbal descriptions for each name by asking two raters to extract specific but nonprobative information from each celebrity photo: ethnicity, sex, hair, generic occupation, and a career-related concrete noun (e.g., the information for John Key would be white male; short brown straight hair; political leader; podium).

Regardless of the format of the nonprobative information that sometimes appeared with celebrity names, subjects had the same task: Half responded to the truth of the claim "This famous person is alive," and the other half to "This famous person is dead." All other aspects of the method were identical to those of Experiment 1B.

Results

Figure 1 shows that photos and verbal descriptions produced a similar truthiness effect. That is, people were more biased 
to respond "true" when nonprobative information accompanied names, $F(1,50)=10.27, \eta_{\mathrm{p}}{ }^{2}=.17$. Claim did not interact with the presence or format of the nonprobative information (all $F_{\mathrm{S}}<1$ ).

\section{Discussion}

These findings show that truthiness is not tied to the perceived credibility of photos. Instead, these results point to a more general mechanism whereby manipulations that facilitate elaboration, against the backdrop of a confirmation bias, lead people to conclude that claims are true. In Experiment 3, we further explored the generalizability of the effect of nonprobative photos on subjective truth, testing the hypothesis that general knowledge claims (e.g., "Turtles are deaf") seem truer when paired with a photo that is related to, but does not specifically depict, the claim.

\section{Experiment 3}

\section{Method}

Subjects In Experiment 3, 70 undergraduate psychology students from Victoria University of Wellington participated for course credit.

Design We used a 2 (photograph: yes, no) $\times 2$ (difficulty: easy, hard) within-subjects design.

Procedure We used trivia statements from previous research and data from preliminary norming to assemble sets of easy and difficult true-false trivia statements that sampled general knowledge (Nelson \& Narens, 1980; Unkelbach, 2007). People answered easy statements correctly $80 \%-100 \%$ of the time and answered difficult statements correctly $40 \%-60 \%$ of the time.

We used the same presentation and response formats as in the prior experiments. On half of the trials, subjects saw a photo that depicted the grammatical subject of the statement but did not provide any diagnostic information about whether the statement was true. For example, the claim that "Macadamia nuts are in the same evolutionary family as peaches" appeared with a photo of macadamia nuts.

\section{Results}

As Fig. 1 shows, photos had the same effect as in our prior experiments: They produced a truthiness effect, $F(1,69)=$ $6.65, \eta_{\mathrm{p}}{ }^{2}=.09$. Although the interaction between difficulty and claim did not reach significance, $F(1,69)=1.82, p=.18$, follow-up analyses supported a conclusion similar to the one from Experiments $1 \mathrm{~A}$ and $1 \mathrm{~B}$, in that the effect was most pronounced when people evaluated difficult rather than easy claims, $t_{\text {diff }}(69)=3.16$, $t_{\text {easy }}(69)=0.85$, n.s.

Although Fig. 1 suggests that Experiments 1A, 1B, and 2 might be interpreted as showing that photos move people toward a neutral bias, Experiment 3 shows that photos move people toward truthiness. In Experiment 3, even without photos, people had a tendency to respond that claims were true, yet the photos still promoted truthiness.

\section{General discussion}

Across four experiments, nonprobative photos inflated truthiness. It is arguably unsurprising that photos inflated the truth of "alive" claims: The photos depicted celebrities alive, and should have facilitated imagery of those celebrities doing various things - all of which would be possible evidence of aliveness. The fascinating finding is that the same photos also inflated the truthiness of "dead" claims: The photos did not produce an "alive bias" but a "truth bias." Moreover, the truthiness effect generalized beyond "dead" or "alive" judgments: Nonprobative photos enhanced the subjective truth of general knowledge claims, too.

The finding that nonprobative verbal information also inflated truthiness suggests that the effect of photos on subjective truth is driven not simply by a perception that photos are inherently trustworthy (cf. Kelly \& Nace, 1994). We speculate that nonprobative photos and verbal information help people generate pseudoevidence. People may selectively interpret information gleaned from a photo or description as consistent with their hypothesis ${ }^{3}$ and/or they may use such information to cue the mental generation of thoughts and images consistent with their hypothesis. It is also possible that the ease or fluency with which people bring related information to mind contributes to a feeling of truthiness. Although we cannot determine which of these mechanisms underlies the truthiness effect, across four experiments our data suggest a general mechanism whereby the availability of related but nonprobative information promotes the truthiness of unfamiliar claims.

Our findings suggest that even without repeated exposures or instructions to imagine, the mere presence of nonprobative information such as photos might rapidly inflate the perceived truth of many types of true and false claims (cf. Brown \& Marsh, 2008; Lindsay et al., 2004). They also suggest that neuroscience claims need not be accompanied by neuroimages to seem more credible: a photo or description of the author might suffice (cf. McCabe \& Castel, 2008).

\footnotetext{
${ }^{3}$ We thank Beth Loftus for raising this possibility.
} 
We view the effects reported here not as qualitatively new phenomena, but rather as lovely new exemplars of a growing family of effects pertaining to inferences (perhaps unconsciously made) regarding the mental generation of hypothesis-consistent evidence (Jacoby, Kelley, \& Dywan, 1989; Johnson, 2006; Schwarz, 2010; Whittlesea, 2011). We describe the photo effect as "lovely" for two reasons. First, as compared to the other "truthiness-inducing manipulations" with which we have experience, the effect of nonprobative photos seems to be quite robust. A robust effect is, of course, an essential tool for theory development, and we hope that future research will use the photo manipulation to explore the specific mechanisms underlying its effect. Second, we believe that it is just plain cool that the same manipulation that can lead people to think that an obscure celebrity is alive can also lead them to think that the celebrity is dead.

Author note We are grateful for the generous support provided by the Marsden Fund and the Natural Sciences and Engineering Research Council of Canada. We thank Christian Unkelbach for kindly sharing his trivia statements for Experiment 3.

\section{References}

Alter, A. L., \& Oppenheimer, D. M. (2009). Uniting the tribes of fluency to form a metacognitive nation. Personality and Social Psychology Review, 13, 219-235.

Begg, I. M., Anas, A., \& Farinacci, S. (1992). Dissociation of processes in belief: Source recollection, statement familiarity, and the illusion of truth. Journal of Experimental Psychology: General, $121,446-458$

Bernstein, D. M. (2005). Making sense of memory. Canadian Journal of Experimental Psychology, 59, 199-208.

Bransford, J. D., \& Johnson, M. K. (1972). Contextual prerequisites for understanding: Some investigations of comprehension and recall. Journal of Verbal Learning and Verbal Behavior, 11, 717-726.

Brown, A. S., \& Marsh, E. J. (2008). Evoking false beliefs about autobiographical experience. Psychonomic Bulletin \& Review, 15, 186-190. doi:10.3758/PBR.15.1.186

Garry, M., Manning, C. G., Loftus, E. F., \& Sherman, S. J. (1996). Imagination inflation: Imagining a childhood event inflates confidence that it occurred. Psychonomic Bulletin \& Review, 3, 208-214.

Gilbert, D. T., Tafarodi, R. W., \& Malone, P. S. (1993). You can't not believe everything you read. Journal of Personality and Social Psychology, 65, 221-233.

Graesser, A. C., \& Hemphill, D. (1991). Question answering in the context of scientific mechanisms. Journal of Memory and Language, 30, 186-209.

Hansen, J., \& Wänke, M. (2010). Truth from language and truth from fit: The impact of linguistic concreteness and level of construal on subjective truth. Personality and Social Psychology Bulletin, 36, 1576-1588. doi:10.1177/0146167210386238

Henkel, L. A., \& Mather, M. (2007). Memory attributions for choices: How beliefs shape our memories. Journal of Memory and Language, 57, 163-176.
Jacoby, L. L., Kelley, C. M., \& Dywan, J. (1989). Memory attributions. In H. L. Roediger III \& F. I. M. Craik (Eds.), Varieties of memory and consciousness: Essays in honour of Endel Tulving (pp. 391422). Hillsdale, NJ: Erlbaum.

Johnson, M. K. (2006). Memory and reality. American Psychologist, $61,760-771$.

Keehner, M., Mayberry, L., \& Fischer, M. H. (2011). Different clues from different views: The role of image format in public perceptions of neuroimaging results. Psychonomic Bulletin \& Review, $18,422-428$.

Kelley, C. M., \& Lindsay, D. S. (1993). Remembering mistaken for knowing: Ease of retrieval as a basis for confidence in answers to general knowledge questions. Journal of Memory and Language, $32,1-24$.

Kelly, J. D., \& Nace, D. (1994). Knowing about digital imaging and believing news photographs. Visual Communications Quarterly, $18,4-5$.

Kunst-Wilson, W. R., \& Zajonc, R. B. (1980). Affective discrimination of stimuli that cannot be recognized. Science, 207, $557-558$.

Lindsay, D. S. (2008). Source monitoring. In H. L. Roediger III \& J. Byrne (Eds.), Learning and memory: A comprehensive reference. Vol. 2: Cognitive psychology of memory (pp. 325-348). Amsterdam: Elsevier.

Lindsay, D. S., Hagen, L., Read, J. D., Wade, K. A., \& Garry, M. (2004). True photographs and false memories. Psychological Science, 15, 149-154.

Masson, M. E. J., \& Loftus, G. R. (2003). Using confidence intervals for graphically based data interpretation. Canadian Journal of Experimental Psychology, 57, 203-220. doi:10.1037/h0087426

McCabe, D. P., \& Castel, A. D. (2008). Seeing is believing: The effect of brain images on judgments of scientific reasoning. Cognition, 107, 343-352.

Nelson, T. O., \& Narens, L. (1980). Norms of 300 general-information questions: Accuracy of recall, latency of recall, and feeling-ofknowing ratings. Journal of Verbal Learning and Verbal Behavior, 19, 338-368. doi:10.1016/S0022-5371(80)90266-2

Nickerson, R. S. (1998). Confirmation bias: A ubiquitous phenomenon in many guises. Review of General Psychology, 2, 175-220.

Schwarz, N. (2010). Meaning in context: Metacognitive experiences. In B. Mesquita, L. F. Barrett, \& E. R. Smith (Eds.), The mind in context (pp. 105-125). New York: Guilford Press.

Sherman, S. J., Cialdini, R. B., Schwartzman, D. F., \& Reynolds, K. D. (1985). Imagining can heighten or lower the perceived likelihood of contracting a disease: The mediating effect of ease of imagery. Personality and Social Psychology Bulletin, 11, 118-127.

Stanislaw, H., \& Todorov, N. (1999). Calculation of signal detection theory measures. Behavior Research Methods, Instruments, \& Computers, 31, 137-149. doi:10.3758/BF03207704

Tversky, A., \& Kahneman, D. (1973). Availability: A heuristic for judging frequency and probability. Cognitive Psychology, 5, 207-232. doi:10.1016/0010-0285(73)90033-9

Unkelbach, C. (2007). Reversing the truth effect: Learning the interpretation of processing fluency in judgments of truth. Psychological Science, 20, 135-138.

Whittlesea, B. W. A. (1993). Illusions of familiarity. Journal of Experimental Psychology: Learning, Memory, and Cognition, 19, $1235-1253$.

Whittlesea, B. W. A. (2011). Remembering under the influence of unconscious expectations. In P. A. Higham \& J. P. Leboe (Eds.), Constructions of remembering and metacognition: Essays in honor of Bruce Whittlesea (pp. 225-236). Houndmills, U.K.: Palgrave Macmillan. 